\title{
Idiopathic Multiple Cranial Neuropathy A Twenty Year Experience
}

\author{
Yasuo IWASAKI and Masao KINOSHITA
}

\begin{abstract}
A report on 8 patients with idiopathic multiple cranial neuropathy is presented. The syndrome consists of headache, facial pain and diplopia preceding the onset of cranial nerve palsy. The cranial nerves most frequently involved were the third, fifth and seventh. All patients were treated with corticosteroid therapy. The symptoms were self-limiting in their course and corticosteroid therapy appeared to hasten recovery of function. Only in a few cases a noticeable neurological deficiency remained. Differential diagnosis and etiological considerations are discussed.
\end{abstract}

Key words: Idiopathic multiple cranial neuropathy, Etiology, Guillain-Barré syndrome, Tolosa-Hunt syndrome

The etiology and pathogenesis of idiopathic multiple cranial neuropathy (IMCN) is often obscure (1-4). In a few cases the syndrome is associated with sarcoidosis (5), diabetes mellitus (6), and tuberculosis (7). Many of the cases have been reported from Asia. Typically, the clinical syndrome is acute in the onset and is characterized by multiple cranial nerve palsy mostly affecting the oculomotor and facial nerves. Symptoms are self-limiting and respond well to the corticosteroid therapy. Sometimes the onset of cranial nerve dysfunction is preceded by infectious process and therefore the possibility of GuillainBarré syndrome is emphasized as an etiological factor (8). There are also same cases in which the syndrome has been shown to be inherited (9). However, there are many possible etiological factors, which may cause the syndrome, in most of the cases the etiology remains unknown in spite of extensive investigations. In this paper, we report our own data on 8 patients with IMCN during a span of twenty years.

\section{MATERIALS AND METHODS}

The patients materials for this paper consists of 8 patients with symptoms and signs of dysfunction of more than one cranial nerve without other pathological findings in neurological examination or any extension in the neurological signs during a longterm follow-up (1). Cases with involvement of a single cranial nerve, congenital cases and those associated with trauma, demyelinating, neuromuscular and cerebrovascular disease were excluded. In spite of extensive investigations, which were properly considered in each case, no clear etiology could be derived. Eight cases of IMCN were identified. The patients were examined many times at the out and in-departments. Both neuro-otological and neuro-ophthalmological examinations were carried out in all of the patients. The following investigations were carried out in all of the patients: Detailed neurological examination, erythrocyte sedimentation rate (ESR), Veneral disease research laboratory tests (VDRL), white blood cell counts (WBC), antinuclear antibody tests (ANA), analysis of cerebrospinal fluid (CSF), skull X-ray, angiography and computed

\footnotetext{
From The Fourth Department of Internal Medicine, Toho University Ohashi Hospital, Tokyo

Received for publication October 13, 1988.

Reprint request to: Yasuo Iwasaki MD, The Fourth Department of Internal Medicine,

Toho University Ohashi Hospital, 2-17-6 Ohashi Meguro-ku, Tokyo 153 Japan
} 
cranial tomography (CT). Also, other routine and special laboratory investigations such as glucose tolerance test, hormonal and immunological tests were carried out.

\section{RESULTS}

There were 4 men and 4 women with IMCN aged 13 to 48 years, though half of cases were in the $3 \mathrm{rd}$ decade (Table 1). All of the patients had previously been in good health and were not exposed to toxic or noxious agents. None had a family history of illness or neurological disorder.

\section{Headache, diplopia and facial pain}

Seven patients had headache. Headache was usually the initial symptom, and tended to be unilateral, usually in the frontal or temporal areas. Five patients had diplopia. Six patients exhibited facial pain. Usually pain commenced few days before the nerve palsy. The pain was aching and unrelating, but never throbbing. In the individual case pain was localized in the earlobe and cheek. Nausea was present only in case 2. Case 5 had dysarthria. None had periorbital edem and conjunctivitis.

\section{Cranial nerves}

Neurological symptoms referable to the affected cranial nerves were usually abrupt in the onset. They included diplopia, ptosis, altered facial sensation and others as might be expected.

The nerves involved were II $(2 / 8)$, III $(7 / 8)$, IV $(3 / 8)$, V (6/8), VI (4/8), VII (6/8), IX (1/8) and X $(1 / 8)$. The VIII, XI and XII were not involved in any of our patients. The most common finding was unilateral ophthalmoplegia and facial palsy on the painful side. Cases 2 and 6 had a transient decrease in vision, although resolved. Unequally reactive pupils were present in 2 of 8 cases. None had papilledema. Ptosis was present in 6 of 8 cases.

\section{Laboratory tests}

Table 2 illustrates a summary of etiological investigations. None had symptoms of diabetes mellitus. All had normal glucose tolerance tests and normal fasting blood sugar concentration. Erythrocyte sedimentation rate (ESR) was normal in 7 cases,

Table 1. Summary of 8 patients with idiopathic multiple cranial neuropathy

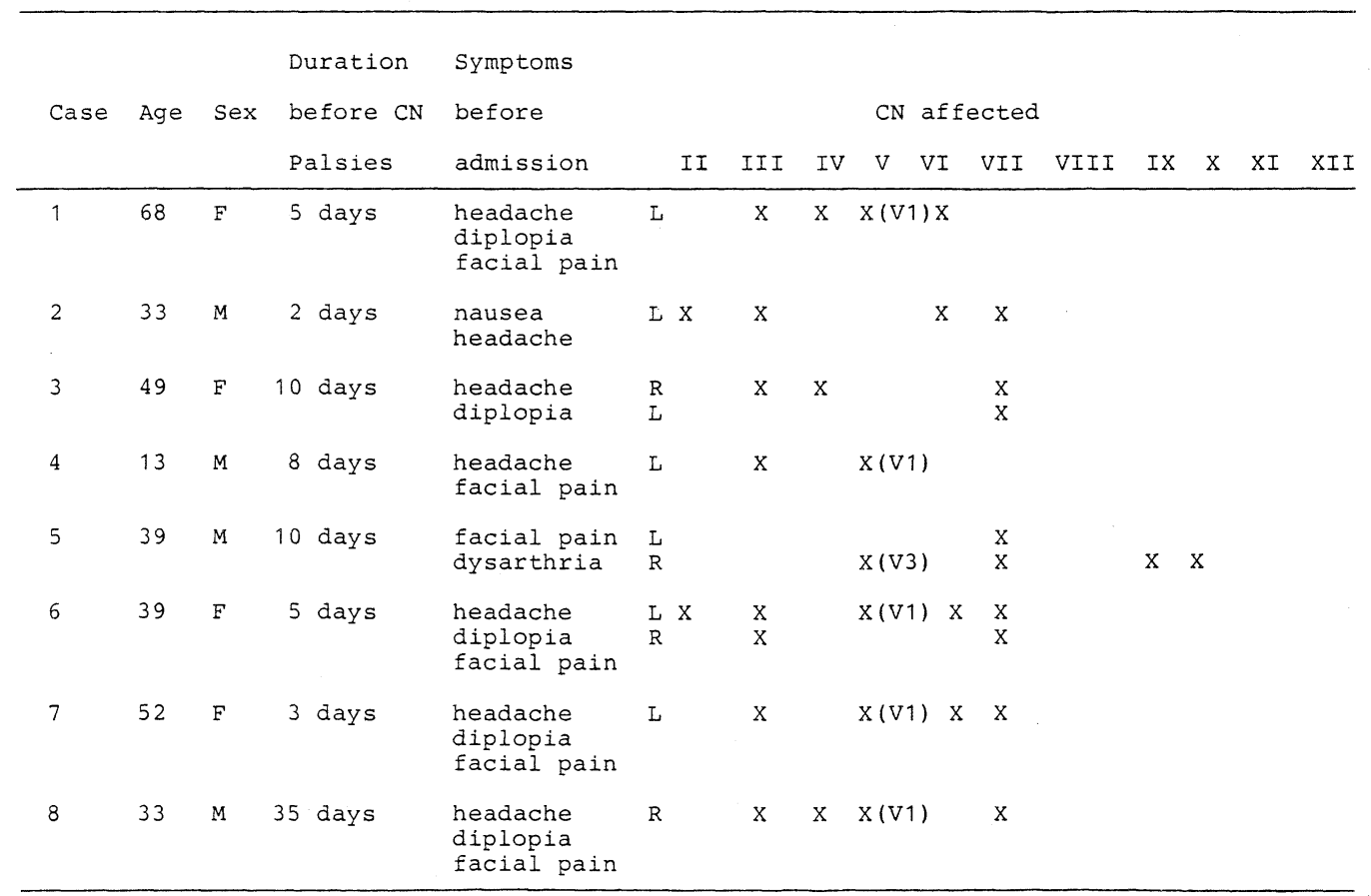

$\mathrm{CN}=$ cranial nerve. $\mathrm{F}=$ female. $\mathrm{M}=$ male. $\mathrm{L}=$ left $. \mathrm{R}=$ right 
Table 2. Summary of etiological investigations

\begin{tabular}{|c|c|c|c|c|c|c|c|c|c|}
\hline \multirow[b]{2}{*}{ Case } & \multirow{2}{*}{$\begin{array}{c}\text { ESR } \\
(\mathrm{mm} / \mathrm{hr})\end{array}$} & \multirow[b]{2}{*}{ VDRL } & \multirow[b]{2}{*}{ WBC } & \multirow[b]{2}{*}{ ANA } & \multicolumn{2}{|c|}{ CSF } & \multicolumn{3}{|c|}{ Radiology } \\
\hline & & & & & $\begin{array}{l}\text { Cells } \\
\text { (cumm }{ }^{3} \text { ) }\end{array}$ & $\begin{array}{c}\text { Proteins } \\
\text { (mg/dl) }\end{array}$ & $\begin{array}{l}\text { Skul1 } \\
\mathrm{X}-\mathrm{ray}\end{array}$ & Angiography & $\overline{C T}$ \\
\hline 1 & 12 & Neg & 5800 & Neg & 5 & 65 & $\mathrm{~N} 1$ & $\mathrm{~N} 1$ & $\mathrm{~N} 1$ \\
\hline 2 & 26 & Neg & 6000 & Neg & 4 & 22 & N1 & $\mathrm{Nl}$ & $\mathrm{NI}$ \\
\hline 3 & 8 & Neg & 5800 & Neg & 10 & 37 & $\mathrm{NI}$ & N1 & $\mathrm{N} 1$ \\
\hline 4 & 7 & Neg & 7400 & Neg & ND & ND & N1 & $\mathrm{N} 1$ & $\mathrm{~N} 1$ \\
\hline 5 & 9 & Neg & 6200 & Neg & 140 & 154 & N1 & $\mathrm{NI}$ & N1 \\
\hline 6 & 5 & $\mathrm{Neg}$ & 3800 & Neg & 7 & 22 & N1 & N1 & $\mathrm{N} 1$ \\
\hline 7 & 3 & Neg & 4200 & Neg & 1 & 44 & $\mathrm{~N} 1$ & $\mathrm{NI}$ & N1 \\
\hline 8 & 4 & Neg & 5600 & Neg & 12 & 31 & $\mathrm{~N} 1$ & $\mathrm{~N} 1$ & N1 \\
\hline
\end{tabular}

$\mathrm{ESR}=$ erythrocyte sedimentation rate. $\mathrm{VDRL}=$ veneral disease research laboratory tests. $\mathrm{WBC}=$ white blood cell counts. ANA = antinuclear antibody tests. $\mathrm{CSF}=$ cerebrospinal fluid. $\mathrm{CT}=$ computed cranial tomography. $\mathrm{ND}=$ not determined. $\mathrm{Neg}=$ negative. $\mathrm{Nl}=$ normal.

while in case 2 it was $26 \mathrm{~mm} / \mathrm{h}$. Veneral disease research laboratory tests (VDRL) and antinuclear antibody tests (ANA) were negative in all cases. All patients had a normal white blood cell count (WBC).

\section{Cerebrospinal fluid}

The cerebrospinal fluid (CSF) was abnormal in 3 of 7 cases with elevation of protein or/and pleocytosis. Protein count was elevated in cases 1 , 5, and 7. Case 5 and 140 mononuclear cells $/$ cumm $^{3}$. Cultures for bacteria and fungi, and cytology were negative in all patients. All showed negative testing results for viral agents.

\section{Neuroradiology}

Skull X-ray, angiography and computed cranial tomography $(\mathrm{CT})$ were normal in all cases.

\section{Corticosteroid response}

Every patient received predonisolon 30 to $60 \mathrm{mg}$ per day. In 6 of them, improvement began within 7 days and in five cases recovery was complete by two months. Case 6 continued to have dilated pupil two years later. There were no reported complications. No patients died and none had recurrence (Table 3).

Table 3. Summary of corticosteroid response

\begin{tabular}{|c|c|c|c|c|c|c|}
\hline Case & $\begin{array}{l}\text { Beginning } \\
\text { of recovery }\end{array}$ & $\begin{array}{l}\text { Duration } \\
\text { of } \mathrm{CN} \text { deficit }\end{array}$ & $\begin{array}{l}\text { Residual } \\
\text { deficit }\end{array}$ & $\begin{array}{l}\text { Steroid } \\
\text { response }\end{array}$ & Relapse & $\begin{array}{l}\text { Follow-up } \\
\text { (months) }\end{array}$ \\
\hline 1 & 5 days & 25 days & None & Yes & No & 60 \\
\hline 2 & 5 days & 45 days & None & Yes & No & 42 \\
\hline 3 & 14 days & $>1$ year & diplopia & Yes & No & 18 \\
\hline 4 & None & $>1.5$ years & dysesthesia of face & No & No & 24 \\
\hline 5 & 6 days & 30 days & None & Yes & No & 31 \\
\hline 6 & 7 days & 2 years & dilated pupils & Yes & No & 27 \\
\hline 7 & 3 days & 7 days & None & Yes & No & 23 \\
\hline 8 & 7 days & 30 days & None & Yes & No & 21 \\
\hline
\end{tabular}

$\mathrm{CN}=$ cranial nerve. 


\section{DISCUSSION}

Multiple cranial nerve palsy may be a manifestation of several known disorders and may occur in sarcoidosis (5), diabetic neuropathy (6), tuberculous meningitis (7), Guillain-Barré syndrome (8) and others; however, many cases remain undiagnosed after extensive investigations. As a clinical entity it is a distinctive syndrome without any underlying disease, and also known as migrating disseminated multiple cranial neuropathy (4). The reports of such are not uncommon in some tropical and a few nontropical areas. We reviewed all cases of IMCN encountered over twenty years. In the literature women were more often affected than men $(1,2,4)$, in our series the male to female ratio was equal. The age of the patients was similar to other cases $(1,2,4)$.

Headache, diplopia and facial pain frequently precede the onset of neurological symptoms. While any of the motor and sensory cranial nerves might be affected, involvement of $3 \mathrm{rd}$, 5th and facial nerves was most common. The VIIIth, IXth and hypoglossal nerves were spared. Facial nerve palsy was seen in six of eight patients and Hokkanen et al. (2) stated that the facial nerve was frequently affected. The symptoms were self-limiting in the course and in most cases full recovery reached in some weeks (2). Corticosteroids hastened the recovery in most cases. Five of our patients (case 1, $2,5,7$ and 8) full recovery was seen within 2 months, otherwise neurological symptoms and signs has been continued for 1 year in two patients (case 3 and 6), and case 4 showed no improvement over a period of years. It is considered that most of cases with IMCN is a clinically benign course but some of IMCN exhibit protracted symptoms and sign in spite of corticosteroid treatment. It should be kept in mind that there is a poor or no steroid responsive cases with IMCN, the resulting spectrum of illness probably reflecting diverse etiologies.

The syndrome of IMCN was recognized by Gowers in this textbook at as early as time 1888 (10). Collier commented (11) on the self-limiting nature of the syndrome and its tendency to recur. In our series, none had a recurrence. Most patients presented a history of headache and facial pain without upper respiratory tract infection preceding the acute onset of the cranial nerve palsy.
In most cases no significant abnormalities were found in blood, CSF and neuroradiology. The CSF showed an albumino-cytologic dissociation with an elevation of protein content and normal count of cells in case 1 and 7, but the Guillain-Barré syndrome could not be verified in either case. Some cases of multiple cranial nerve palsy may represent oligosymptomatic forms of the Guillain-Barré syndrome (8).

Nevertheless, in their patients, pain was not a feature, and they frequently exhibited cerebellar symptoms and signs in addition to cranial nerve palsy. None of our patients showed cerebellar symptoms and signs. Although cranial nerve palsy has been reported as a complication of diabetes mellitus (6), none of our patients had abnormal fasting blood sugar concentration and glucose tolerance tests. A careful search for evidence of tuberculosis, fungi, sarcoidosis and dysglobulinemia proved negative, nor could collagen disease be verified in patients with suspicious history of illness. Viral infections have been reported to cause isolated cranial nerve abnormalities $(12,13)$, but all showed negative in serological and CSF testing for viral agents. Carcinomatous meningitus may cause multiple cranial nerve signs (14), but in our cases no atypical cells were seen by CSF cytology.

In 1961 Hunt et al. (15) reported six cases from the United States who suffered a syndrome of focal cranial nerve palsy by recurrent unilateral retroorbital pain with ocular palsy, hypoaesthesia in the area supplied by the first division of the trigeminal nerve, and occasional blindness. Headache or eye pain preceded the ophthalmoplegia, symptoms lasted from several days to weeks, spontaneous remission occurred, and attacks recurred at irregular intervals over several years.

The only distinguishing criterion from IMCN therefore, requires that structures involved be confined to the cavernous sinus. Steele and Vasuvat noted (3) that their cases of IMCN were similar to cases designated as the Tolosa-Hunt syndrome.

Further, pathological confirmation is needed to clarify these two clinical syndromes.

The patients of the present series represent IMCN. A careful search for systemic diseases proved negative. It should be clear that recognition of the syndrome of IMCN allows few diagnostic shortcuts, 
suggesting the etiologically nonspecific nature of its presentation.

\section{REFERENCES}

1) Juncos JL and Beal MF: Idiopathic cranial polyneuropathy: a fifteen-year experience. Brain 110: 197, 1987.

2) Hokkanen E, Haltia T and Myllylä VV: Recurrent multiple cranial neuropathies. Eur Neurol 17: 32, 1978.

3) Steele JC and Vasuvet A: Recurrent multiple cranial nerve palsies: a distinctive syndrome of cranial polyneuropathy. J Neurol Neurosurg Psychiatry 33: $828,1970$.

4) Takahashi A: Migrating disseminated multiple cranial neuropathy (in Japanese). Clin Neurol (Tokyo) 14: 835, 1974.

5) Takagi S, Komiya $\mathrm{H}$ and Honda $\mathrm{M}$ : Sarcoidosis with neurological signs (in Japanese). Clin Neurol (Tokyo) 12: $282,1972$.

6) Larson DL and Auchinclose JH: Multiple symmetrical bilateral cranial nerve palsies in patients with unregulated diabetes mellitus. Arch Intern Med 85: 120,
1950.

7) Ratnavale GS: Cranial polyneuritis. Proc Aust Assoc Neurol 5: 527, 1968.

8) Munsat TL and Barnes JE: Relation of multiple cranial nerve dysfunction to the Guillain-Barré syndrome. J Neurol Neurosurg Psychiatry 28: 115, 1965.

9) Lisch K: Familiäres Auftreten von rezidierenden Fazialisparesen mit Augenmuskelparesen. Klin Mbl Augenheik 155: 400, 1969.

10) Gowers WR: A manual of diseases of the nervous system. London: J and A Churchill 1988.

11) Collier J: Discussion on ocular palsies. Proceeding of the Royal Society of Medicine 14: 10, 1921.

12) Cassell GH and Cole BC: Mycoplasms as agents of human disease. N Eng J Med 304: 80, 1981.

13) Grose C, Henle W, Henle G, et al: Primary EpsteinBarre virus infections in acute neurologic diseases. $\mathrm{N}$ Eng J Med 292: 392, 1975.

14) Thomas JE and Yoss RE: The parasellar syndrome: Problems in determining etiology. Mayo Clin Proc 45: 617, 1970.

15) Hunt WE, Meagher JN, LeFever HE, et al: Painful ophthalmoplegia: its relation to indolent inflammation of the cavernous sinus. Neurology 11: 56, 1961. 